\title{
Malpractice and socioeconomic aspects in neurosurgery: a developing-country reality
}

\author{
Leonardo J. M. de Macêdo Filho, MD, ${ }^{1}$ Ana Carolina A. Aragão, MD, ${ }^{1}$ lan A. Moura, MD,1 \\ Lucas B. Olivier, BS, ${ }^{2}$ and Lucas Alverne F. Albuquerque, MD $^{3}$ \\ ${ }^{1}$ University of Fortaleza, Health Science Center, Fortaleza; ${ }^{2}$ Federal University of Ceará, Department of Mathematics, Fortaleza; \\ and ${ }^{3}$ General Hospital of Fortaleza, Department of Neurosurgery, Fortaleza, Ceará, Brazil
}

OBJECTIVE Neurosurgery occupies a prominent place in medical malpractice, but cases are still underreported in Brazil. This study describes the socioeconomic issues of medical malpractice in neurosurgery procedures and how they culminate in unfavorable outcomes in a developing country.

METHODS The authors analyzed 112 neurosurgical procedures listed in the Brazilian Hospital Information System (Sistema de Informações Hospitalares do Sistema Único de Saúde [SIHSUS]) records in the DATASUS (Departamento de Informática do SUS) database between January 2008 and February 2020. Malpractice data were collected using the JusBrasil platform, with the authors searching the name of each of the 112 neurosurgical procedures plus "medical malpractice" among the jurisprudence records for January 2008 to February 2020. A simple linear regression analysis was performed using appropriate software. Analyses were considered statistically significant at $p<0.05$.

RESULTS According to DATASUS, 842,041 neurosurgical procedures were performed by the Brazilian Unified Health System between January 2008 and February 2020. The mean hospitalization cost for neurosurgical procedures was $\$ 714.06$, and the average amount paid to professionals per procedure was $\$ 145.28$ with variations according to the type of practice (public or private) in which they were performed, the complexity of the procedure, and the Brazilian region. The mortality rate and mean length of stay for neurosurgical procedures were $11.37 \%$ and 10.15 days, respectively. There were 79 medical malpractice lawsuits in the studied period. In these lawsuits, $26.58 \%$ of the court decisions were unfavorable to the neurosurgeons, with a mean compensation per procedure 15 times higher than the median value paid for all professionals in a neurosurgical procedure. The spine subspecialty had more lawsuits, and the brain tumor subspecialty had the most expensive compensation.

A lack of resources in public healthcare negatively impacts inpatient care. The mortality rate was 1.5 times higher in public practice than in private practice and was inversely proportional to the MTCs paid for the neurosurgical procedure. Patients with the lower educational levels associated with limited access to good medical care could reflect the lower plaintiff motivation in regions with a low gross domestic product and Human Development Index. In most cases, there is no understanding from either the patient or his family about the health-disease process, nor that there was medical malpractice committed by the physician to be sued.

CONCLUSIONS The socioeconomic inequalities and the population's low awareness of their rights could explain the few malpractice cases reported in Brazil. The authors recommend better decisions regarding the investments to be made in neurosurgical procedures to reduce malpractice lawsuits.

https://thejns.org/doi/abs/10.3171/2020.8.FOCUS20571

KEYWORDS malpractice; neurosurgery; socioeconomic factors; developing countries

$\mathrm{M}$ EDICAL malpractice is an adverse event or outcome resulting from a medical action or its omission due to unskillfulness, neglect, or imprudence, correlating ethical and legal aspects. ${ }^{1-3}$ Neurosurgery has one of the highest proportions of malpractice lawsuits in the United States annually. The average com- pensation paid is also considerably higher in neurosurgery than in other specialties. ${ }^{4,5}$ A lack of adequate communication with patients and family members to understand their expectations about a neurosurgical procedure could explain the higher litigation rates. ${ }^{6}$

Medical malpractice events are still underreported in

ABBREVIATIONS DATASUS = Departamento de Informática do SUS; GDP = gross domestic product; HDI = Human Development Index; MTC = mean total cost; SUS = Brazilian Unified Health System (Sistema Único de Saúde).

SUBMITTED June 23, 2020. ACCEPTED August 24, 2020.

INCLUDE WHEN CITING DOI: 10.3171/2020.8.FOCUS20571. 
Brazil. 7 The National Justice Council (Conselho Nacional de Justiça [CNJ]) registered 26,000 lawsuits for medical malpractice last year, and 54,076 patients died in 2017 due to medical malpractice. ${ }^{8}$ The systematization of evidence on health costs and outcomes has become a key issue for enabling better decisions regarding investments in equipment, supplies, and personnel. ${ }^{9-12}$

Here, we correlate socioeconomic issues (i.e., discrepancies in Brazilian regions, the public and private practice of health, mean total cost [MTC] in neurosurgical procedures) and hospital outcomes (i.e., mortality rate and length of stay) with medical malpractice in neurosurgical procedures in Brazil.

\section{Methods \\ Data Collect}

We analyzed 112 neurosurgical procedures listed in the Brazilian Hospital Information System (Sistema de Informações Hospitalares do Sistema Único de Saúde [SIHSUS]) records in the DATASUS (Departamento de Informática do SUS) database between January 2008 and February 2020. DATASUS is the information technology department of the Brazilian Unified Health System (Sistema Único de Saúde; SUS), and the database was developed and is maintained by the Brazilian federal government. ${ }^{13}$ It collects, processes, disseminates, and manages health information from the public sector under the SUS as well as from the private sector. DATASUS is an administrative database with information from all hospitalizations reimbursed by the SUS..$^{14}$

The Brazilian federal government divided its 27 federation units (26 states and 1 federal district) into 5 geographic regions (i.e., North, Northeast, Midwest, Southeast, and South), proposing to help in the management and application of public policies. These geographic regions present differences in gross domestic product (GDP) and Human Development Index (HDI). ${ }^{15}$ For each Brazilian region and healthcare sector (public or private), we analyzed the following categories for each neurosurgical procedure: number of patients, complexity of the procedure, mean hospitalization cost, mean professional cost, MTC, mortality rate, total number of deaths, mean length of stay, and total length of stay (days). For international comparison, we converted the Brazilian real $(\mathrm{R} \$)$ to the United States dollar (US\$). The corresponding dollar exchange rate on the day of data collection (May 10,2020) was $R \$ 1$ equivalent to US\$0.18. We used the Ceará Department of Health (Secretaria da Saúde do Estado do Ceará [SESA]) classification to determine the complexity of procedures (mild, moderate, or high) and the DATASUS records for the other studied indicators. The mortality rate is the hospital mortality rate per 100 people hospitalized for the neurosurgical procedure. The mean length of stay is the sum of the days from admission to the day of discharge divided by the number of patients hospitalized for each neurosurgical procedure.

We collected the malpractice data using the JusBrasil, a private virtual platform that compiles Brazilian lawsuits from Brazilian competent legal bodies (state institutions and supreme court). ${ }^{16}$ We searched the name of each of the
112 procedures mentioned in DATASUS plus "medical malpractice" among the jurisprudence records for January 2008 to February 2020. We only included medical malpractice lawsuits related to these 112 neurosurgical procedures, and we excluded lawsuits that had no relation to these procedures as well as cases of malpractice related to other underlying pathologies rather than exclusively related to the neurosurgical procedure.

We divided the medical malpractice in neurosurgical procedures data into subspecialties (brain tumor, functional, pediatric, skull base, spine, trauma/emergency, and vascular) and studied the following categories: medical malpractice lawsuits, medical malpractice compensations, mean malpractice compensations, MTC, mortality rate, and mean length of stay.

\section{Statistical Analysis}

We performed a simple linear regression analysis using the software Prism 7.0 (GraphPad Software Inc.). The results were expressed with scatter plots and slope lines \pm standard error and $95 \%$ confidence intervals. We considered the linear regression analyses statistically significant at $\mathrm{p}<0.05$.

We compared mortality rate with MTC and mean length of stay for the neurosurgical procedures and performed a residual analysis of cases with a mortality rate $\geq 10 \%$. Moreover, we evaluated the most frequently performed neurosurgical procedures, MTCs, and medical malpractice data.

\section{Results}

\section{Socioeconomic Factors and Patient Outcomes in Neurosurgical Procedures}

There are a total of 4836 neurosurgery beds in Brazil: 3472 beds in the SUS (public and universal health coverage) and 1364 beds in the private sector. According to DATASUS, 842,041 neurosurgical procedures (mean of 5807.17 procedures/month) were performed in the SUS between January 2008 and February 2020 (145 months; Supplemental Table 1). The mean hospitalization cost for neurosurgical procedures was $\$ 714.06$. Moreover, the average amount paid to professionals (i.e., doctors, nurses, and nursing assistants) per procedure was $\$ 145.28$. These values differed according to the type of practice in which the procedure was performed (i.e., public or private) and the geographic region of Brazil in which the procedure was performed (Table 1).

The most frequently performed procedures were ventricular shunt placement for the peritoneum/atrium/pleura (11.14\%), external ventricular/subgaleal shunt placement (10\%), surgical treatment of acute subdural hematoma (6.74\%), surgical treatment of chronic subdural hematoma $(6.27 \%)$, and nonfunctional neurolysis of peripheral nerves (4.92\%; Fig. 1). The most expensive procedure was embolization of a wide-necked cerebral aneurysm of 8-15 mm (\$4119.98), and the cheapest procedure was nonfunctional neurolysis of peripheral nerves (\$99.90; Fig. 2).

There were 95,725 hospital deaths from January 2008 to February 2020 (mean of 660.17 deaths/month), and the mortality rate was $11.37 \%$. The North region $(12.9 \%)$ had 
TABLE 1. Economic and patient statistics for neurosurgical procedures between January 2008 and February 2020 from the Hospital Information System in Brazil

\begin{tabular}{cccccc}
\hline Variable & Mean Hospitalization Cost (US\$) & Mean Professional Cost (US\$) & MTC (US\$) & Mortality Rate & Mean LOS (days) \\
\hline Region & & & & & \\
\hline North & $\$ 661.18$ & $\$ 161.51$ & $\$ 822.69$ & 12.9 & 12.3 \\
\hline Northeast & $\$ 710.17$ & $\$ 148.49$ & $\$ 858.66$ & 11.36 & 10.5 \\
\hline Southeast & $\$ 752.40$ & $\$ 149.49$ & $\$ 901.89$ & 12.25 & 10.6 \\
\hline South & $\$ 767.84$ & $\$ 146.42$ & $\$ 914.26$ & 8.94 & 8.4 \\
\hline Midwest & $\$ 681.67$ & $\$ 157.80$ & $\$ 839.47$ & 11.47 & 10.4 \\
\hline Practice & & & & & \\
\hline Public & $\$ 677.29$ & $\$ 142.89$ & $\$ 820.18$ & 14 & 12.5 \\
\hline Private & $\$ 778.89$ & $\$ 146.29$ & $\$ 925.19$ & 9.24 & 8.5 \\
\hline
\end{tabular}

LOS = length of stay.

the highest mortality rate, and the South region had the lowest (8.94\%; Table 1). The mortality rate was $14 \%$ in public hospitals, while the rate in private hospitals was $9.24 \%$. The mortality rate was 1.5 times higher in public hospitals than in private hospitals and was inversely proportional to the MTCs paid for the neurosurgical procedure. The neurosurgical procedures with the higher mortality rates were surgical treatment for intracerebral hematoma (35.13\%), surgical treatment for intracerebral hematoma with a complementary technique (32.21\%), decompressive craniotomy (31.91\%), external ventricular/ subgaleal shunt placement (29.22\%), and cranial trepanation for ICP monitoring (26.81\%; Supplemental Table 1).

The total length of stay was $8,614,673$ days (mean of 10.15 days/neurosurgical procedure hospitalizations) between January 2008 to February 2020. The mean length of stay was 8.5 days in private hospitals but 12.5 days in public hospitals. Moreover, these values were different in each geographic region of Brazil (Table 1).

Trauma/emergency procedures had the highest mortality rate $(12.66 \%)$, followed by brain tumor procedures (7.43\%). The mean length of stay was highest for brain tumor procedures (13.81 days), followed by trauma/emergency procedures (12.95 days; Table 2 ).

We classified 69 neurosurgical procedures as high complexity, 28 as moderate complexity, and 15 as mild complexity (Supplemental Table 1). We performed a linear regression analysis of the relationship between mortality rate and the MTCs paid for all neurosurgical procedures and categorized our findings by procedure complexity. We found a significant $\mathrm{p}$ value in the high $(\mathrm{p}=0.0014)$, moderate $(\mathrm{p}<0.0001)$, and mild $(\mathrm{p}<0.0001)$ procedural complexities (Fig. 3A-D). We compared the residual values of the neurosurgical procedures separately by complexities, evaluating the cost-effectiveness of the neurosurgical procedures among cases with a mortality rate $\geq 10 \%$. The intracranial angioplasty in vasospasm, microsurgery for an aneurysm of the posterior brain circulation, and cranial trepanation for neurosurgical propaedeutics or therapeutics suggest that the low MTC could impact the mortality rate in these procedures.

We performed a linear regression analysis of the relationship between mortality rate and mean length of stay and categorized our findings according to procedure complexity (high, $\mathrm{p}<0.0001$; moderate, $\mathrm{p}=0.0639$; mild, $\mathrm{p}=$ 0.0088 ). We compared the residual values of the neurosurgical procedures separately by complexities, evaluating the length of stay among cases with a mortality rate $\geq 10 \%$. We found 5 neurosurgical procedures for which a prolonged length of stay could impact the mortality rate (Fig. 3E-H).

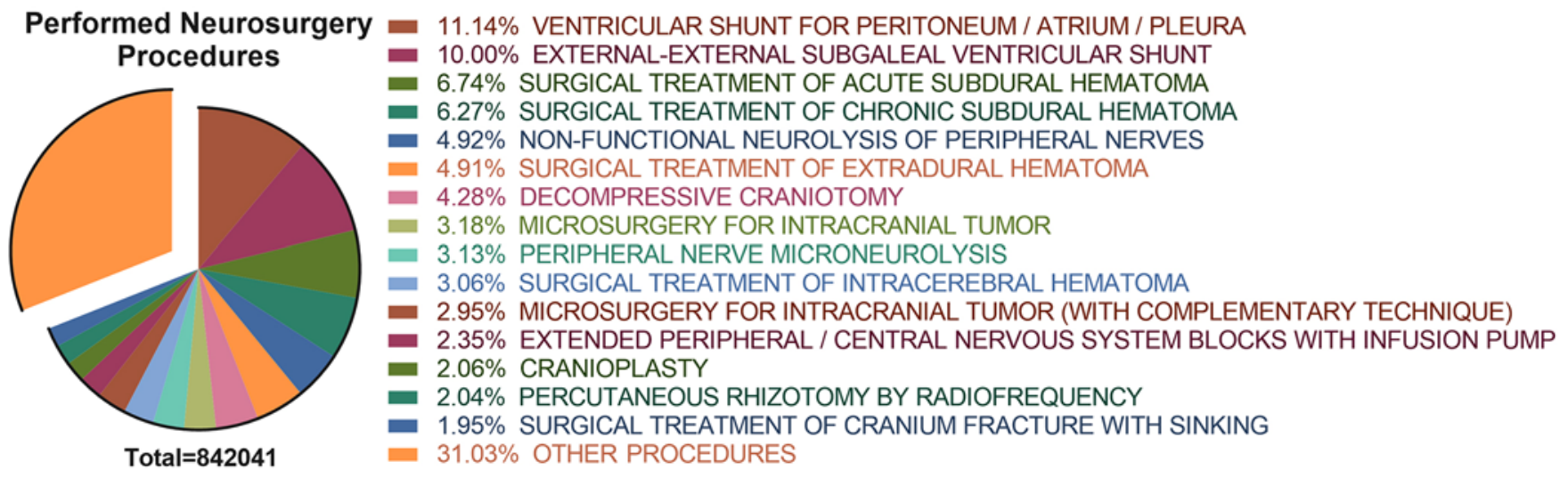

FIG. 1. The most frequently performed neurosurgery procedures between January 2008 and February 2020. 


\section{A Higher MTC Procedures}
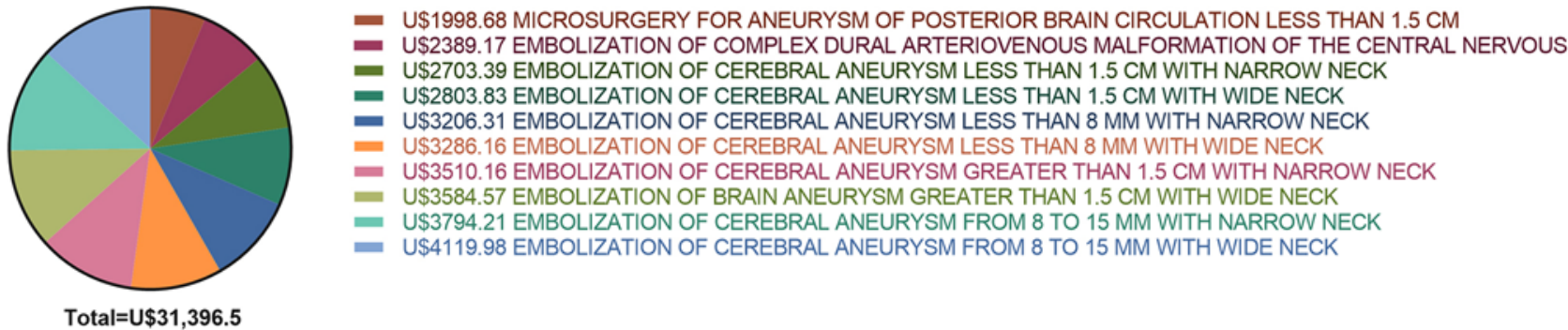

B Lower MTC Procedures
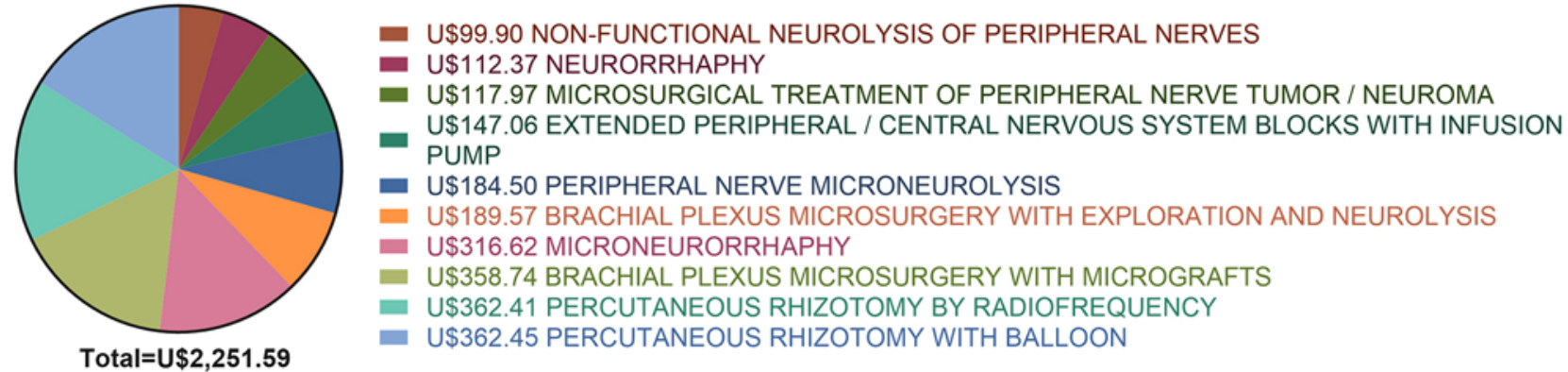

FIG. 2. A: Higher MTCs of neurosurgical procedures. B: Lower MTCs of neurosurgical procedures.

\section{Malpractice in Neurosurgery Procedures}

Between January 2008 and February 2020, there were 79 medical malpractice lawsuits (0.54 cases/month) exclusively for the procedures cited in the DATASUS data- base, $0.0093 \%$ of all neurosurgical procedures performed in this period. In these malpractice lawsuits, $26.58 \%$ (n $=21 / 79$ ) of the court decisions were unfavorable to the neurosurgeons, with total compensation of $\$ 185,364$ for

TABLE 2. Malpractice in neurosurgical procedure lawsuits between January 2008 and February 2020 in Brazilian courts

\begin{tabular}{|c|c|c|c|c|c|c|}
\hline $\begin{array}{l}\text { Neurosurgery Subspecialty } \\
\text { \& Complexity }\end{array}$ & $\begin{array}{l}\text { No. of Medical Malpractice } \\
\text { Lawsuits (\%) }\end{array}$ & $\begin{array}{l}\text { Medical Malpractice } \\
\text { Compensation (US\$) }\end{array}$ & $\begin{array}{c}\text { Mean Malpractice Compensation } \\
\text { per Procedure (US\$) }\end{array}$ & $\begin{array}{l}\text { Mortality } \\
\text { Rate }\end{array}$ & $\begin{array}{l}\text { MTC } \\
\text { (US\$) }\end{array}$ & $\begin{array}{l}\text { Mean LOS } \\
\text { (days) }\end{array}$ \\
\hline Brain tumor & $7(8.86)$ & 32,400 & 4050 & 7.43 & 944.82 & 13.81 \\
\hline High & 7 & 32,400 & 5400 & 6.00 & 992.60 & 13.18 \\
\hline Moderate & 0 & 0 & 0 & 11.72 & 801.49 & 15.70 \\
\hline Functional & $5(6.33)$ & 28,080 & 1652 & 0.85 & 1125.93 & 7.16 \\
\hline High & 5 & 28,080 & 1652 & 0.85 & 1125.93 & 7.16 \\
\hline Pediatric & $2(2.53)$ & 3,600 & 1800 & 1.02 & 537.84 & 6.60 \\
\hline High & 1 & 3,600 & 3600 & 0.82 & 680.48 & 6.70 \\
\hline Moderate & 1 & 0 & 0 & 1.22 & 395.20 & 6.50 \\
\hline Skull base & $1(1.27)$ & 0 & 0 & 2.94 & 1005.48 & 12.48 \\
\hline High & 1 & 0 & 0 & 3.15 & 1060.89 & 12.40 \\
\hline Moderate & 0 & 0 & 0 & 2.12 & 783.87 & 12.80 \\
\hline Spine & $31(39.24)$ & 59,400 & 2376 & 1.75 & 530.18 & 7.12 \\
\hline High & 13 & 25,200 & 1938 & 2.12 & 622.14 & 8.22 \\
\hline Mild & 18 & 34,200 & 4886 & 1.18 & 288.14 & 4.06 \\
\hline Moderate & 0 & 0 & 0 & 1.58 & 629.93 & 8.58 \\
\hline Trauma/emergency & 26 (32.91) & 49,284 & 1825 & 12.66 & 746.86 & 12.95 \\
\hline Mild & 4 & 0 & 0 & 12.56 & 675.55 & 12.39 \\
\hline Moderate & 22 & 49,284 & 2594 & 12.70 & 776.89 & 13.19 \\
\hline Vascular & $7(8.86)$ & 12,600 & 450 & 6.63 & 1982.64 & 10.75 \\
\hline High & 7 & 12,600 & 450 & 6.63 & 1982.64 & 10.75 \\
\hline Total & 79 & 185,364 & 1655 & 5.91 & 1086.93 & 10.15 \\
\hline
\end{tabular}



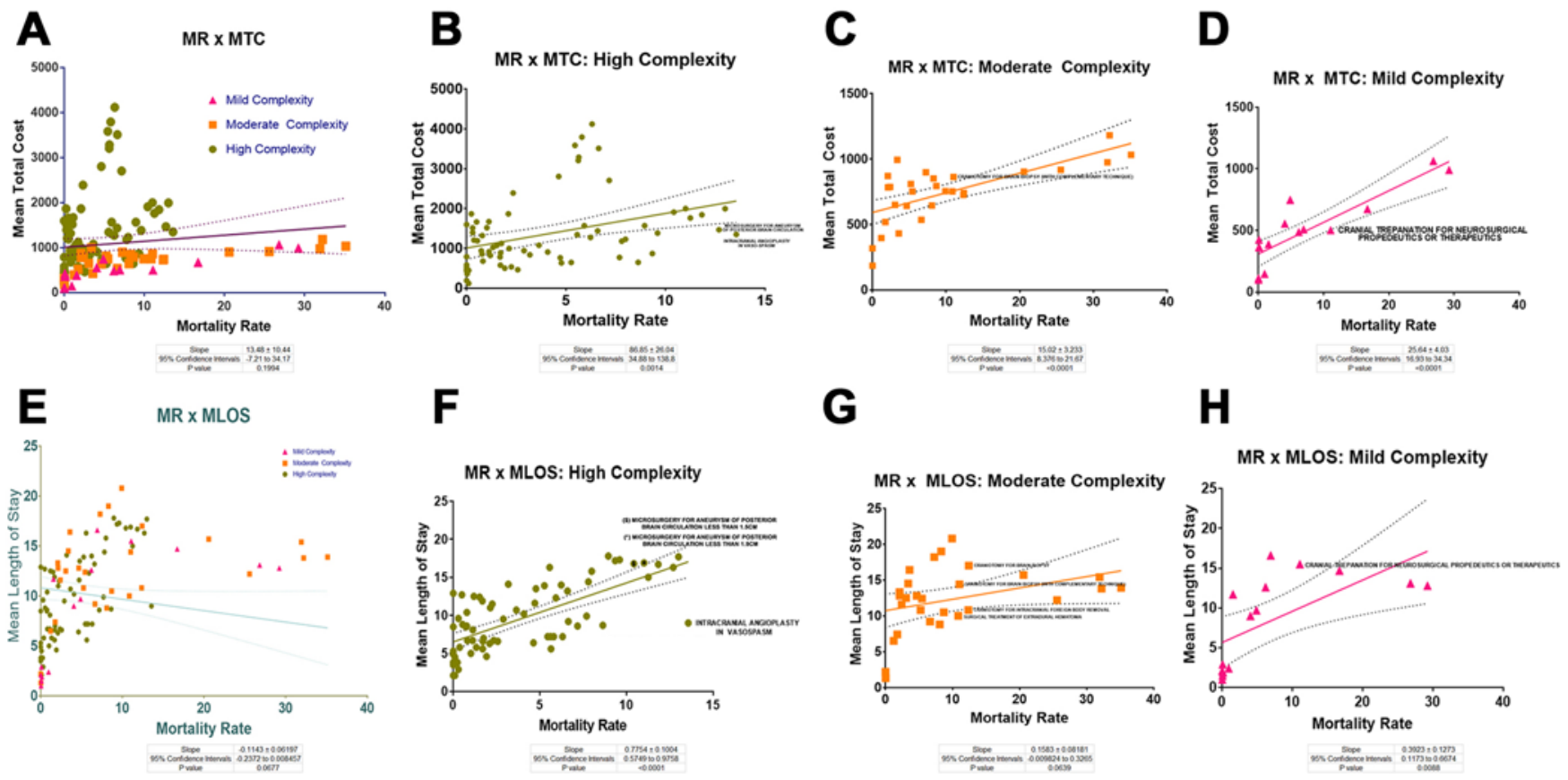

FIG. 3. Neurosurgical procedures regression line for the mortality rate (MR) versus the MTCs paid: all procedural complexities (A) and high-complexity (B), moderate-complexity (C), and mild-complexity (D) procedures. Neurosurgical procedures regression line for the mean length of stay (MLOS) versus the MR: all procedural complexities $(\mathrm{E})$ and high-complexity $(\mathbf{F})$, moderate-complexity $(\mathbf{G})$, and mild-complexity $(\mathbf{H})$ procedures.

these medical malpractice lawsuits. The mean value per neurosurgical procedure was $\$ 2346-15$ times more than the average value paid for all professionals in a neurosurgical procedure $(\$ 145.28)$.

There was 1 malpractice lawsuit in the Northeast $(1.26 \%), 2$ in the North $(2.53 \%), 10$ in the Midwest (12.66\%), 23 in the South (29.11\%), and 43 in the Southeast (54.43\%; Fig. 4). The procedure with the most medical malpractice lawsuits was ventricular shunt placement for the peritoneum/atrium/pleura (17.72\%), followed by microsurgical treatment of a peripheral nerve tumor/neuroma $(12.66 \%)$ and nonfunctional neurolysis of peripheral nerves $(12.66 \%)$. The procedures with most expensive lawsuit compensations were decompressive craniotomy $(\$ 49,284)$, craniotomy to remove an inclusive brain tumor from the posterior fossa $(\$ 27,000)$, and microsurgical treatment of peripheral nerve tumor/neuroma $(\$ 19,800$; Fig. 4).

The neurosurgical subspecialties with more lawsuits were spine $(39.24 \%)$ and trauma/emergency $(32.91 \%)$. The most expensive compensation per procedure was found in the brain tumor subspecialty (\$4050), and the MTC was lower in the spine procedures (\$530.18) despite a high number of lawsuits (Table 2).

\section{Discussion}

Universal healthcare is guaranteed by the 1988 Brazilian Constitution, and everyone (citizen or not) has access to public healthcare from the SUS in Brazil. ${ }^{17}$ In 2000, the supplementary health program that involves the operation of private health insurance plans was created in consolida- tion with the SUS. Nowadays, the private sector covers the healthcare needs of about $24.2 \%$ of the Brazilian population. $^{18}$

A lack of resources in public healthcare negatively impacts inpatient $\operatorname{care}^{19}$ and raises the risk of patient harm, even for competent doctors. ${ }^{20}$ The distribution of resources in the public health service is outdated compared with that in the private service, creating a deficit between the necessary and the available resources for effective health management. ${ }^{21}$ In our study, we found an important contrast between these two different practices (public and private) in neurosurgery procedures. For example, the mortality rate was 1.5 times higher in public hospitals than in private hospitals and was inversely proportional to the MTCs paid for the neurosurgical procedure.

The damage to the patient can have traumatic and irreversible effects on ethical processes. Health expenses resulting from adverse events represent a serious burden in terms of an increase in the hospital stay, in mortality, and in the repercussions, with long litigious actions, bringing moral, financial, and organizational losses. ${ }^{22}$

In general, higher-complexity procedures require more investments in equipment, supplies, and personnel, although they are not the only factor that influences higher costs. The index hospitalization, readmissions, physician services, and postdischarge ancillary care are important in determining the total cost. ${ }^{21}$ Regional differences in Brazil determine the unequal distribution of hospital resources. Regions with a higher GDP (i.e., the South and Southeast) have more hospitals, and greater resources are destined for these institutions. ${ }^{23}$ Hospitals with a higher volume of 


\section{A Medical Malpractice: Decisions}

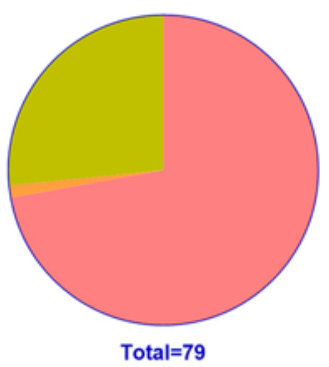

C Medical Malpractice Lawsuit

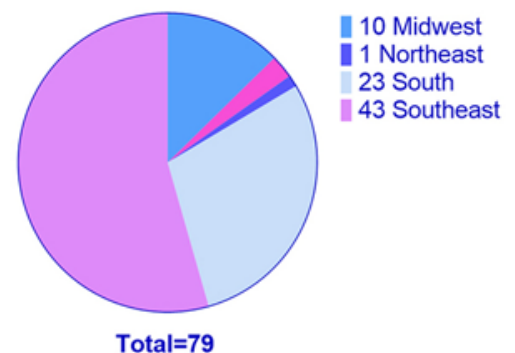

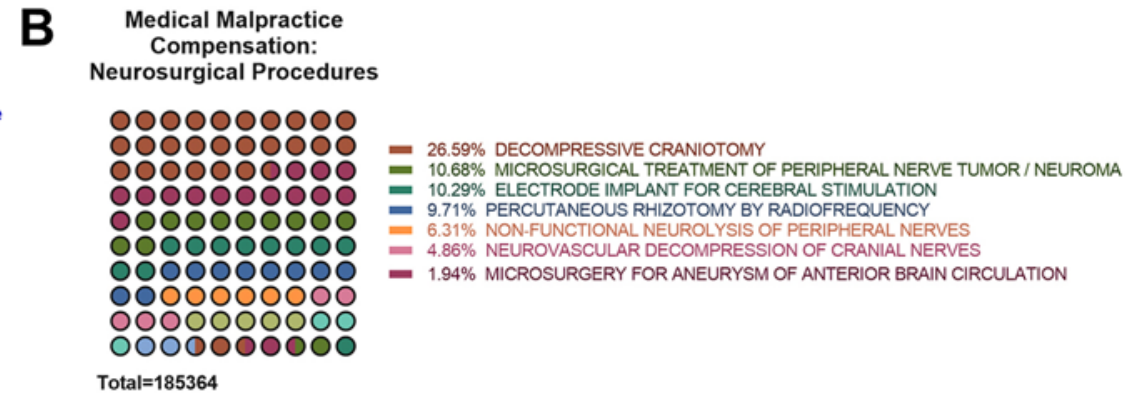

D Medical Malpractice Compensation: Regions

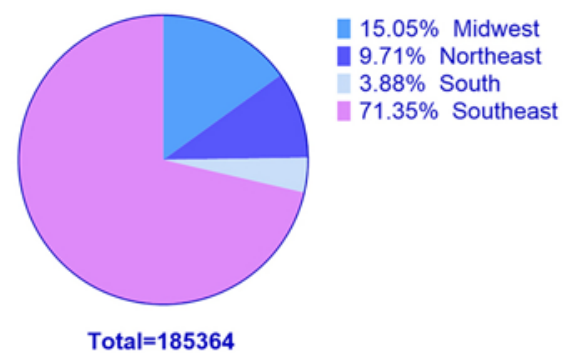

FIG. 4. Medical malpractice: favorable or unfavorable court decisions for the neurosurgeon (A); neurosurgical procedures with the most expensive compensation for medical malpractice lawsuits paid by neurosurgeons (B); malpractice lawsuits divided by Brazilian regions (C); compensation for medical malpractice lawsuits paid by neurosurgeons in each Brazilian region (D).

neurosurgical procedures provide better care and perform more complex procedures with better cost-effectiveness. ${ }^{24}$

There are few studies comparing the cost-effectiveness of neurosurgical procedures in medical malpractice. More studies on the subject should be encouraged to help better manage hospital expenses and reduce morbidities, mortality, length of hospital stay, ${ }^{25,26}$ and, consequently, medical malpractice lawsuits. ${ }^{22}$ Our data showed a significant correlation of MTC with the mortality rate for each complexity (mild, moderate, and high). Among cases with a high mortality rate $(\geq 10 \%)$, our analysis showed 3 neurosurgical procedures with a low MTC and a high mortality rate (Fig. 3A-D).

The higher mortality rate is associated with an increase in the length of hospital stay, especially in ICU beds, ${ }^{27}$ although patient status (i.e., age, presence of comorbidities, and nutritional status); hospital investments in equipment, supplies, and personnel; and procedure complexity influence the length of stay. ${ }^{28}$ In the present study, there was a $47.1 \%$ increase in the mean length of stay and an increase of $51.51 \%$ in the mortality rate in public compared to private hospitals. We also found a significant correlation between mortality rate and length of stay in high- and mildcomplexity procedures. Among cases with a high mortality rate $(\geq 10 \%), 5$ procedures showed greater length of stay values, and 3 procedures showed shorter lengths of stay (Fig. 3E-H); this could be related to procedures that led to a worse overall survival. ${ }^{28}$

Improving our knowledge about malpractice in neurosurgery is extremely important because our specialty is among the most likely to be prosecuted for bad medical practice. In the United States, 19.1\% of practicing neuro- surgeons account for at least one malpractice lawsuit over a period of 1 year. ${ }^{5}$ We can hypothesize that the rate is this high because neurosurgical procedures are more delicate and complex and have a high risk of complications. In addition, neurosurgical patients suffer from pathologies more prone to disabling sequelae. Moreover, neurosurgical practice experience and responsibility can be more prone to a claim of malpractice., ${ }^{49}$

In Brazil, $6.9 \%$ of physicians are sued every year, and $7.14 \%$ of these lawsuits are malpractice cases in neurosurgery. ${ }^{30}$ In our study, we identified 842,041 neurosurgical procedures performed by the SUS between January 2008 and February 2020, with only 79 lawsuits against physicians who performed neurosurgical procedures in that period.

A plaintiff's motivation to start a lawsuit against a neurosurgeon is related to numerous factors. There must be medical malpractice in the procedure according to the patient's or their family's understanding, whether due to negligence, imprudence, or lack of expertise. In addition, factors such as the fragility of the doctor-patient relationship, media influence, and the population's awareness of their rights directly influence the decision to pursue a case. ${ }^{31}$

The different regions of Brazil have deep social and economic inequalities resulting from the combination of social and economic policies associated with regional development strategies. ${ }^{23}$ The search for courts of justice in developed states is higher than in the less developed states. ${ }^{32}$ Low GDP and HDI regions (i.e., the North, Northeast, and Midwest) had only 13 medical malpractice cases, compared with 66 cases in high GDP and HDI regions (i.e., the South and Southeast). 
Despite the new social posture in Brazil, which is based on a process of strengthening citizenship and consumer protection instruments and awakening in individuals the notion of their rights, ${ }^{33}$ patients with the lower educational levels associated with limited access to good medical care could reflect the lower plaintiff motivation in regions with low GDP and HDI. ${ }^{34,35}$ In most cases, there is no understanding from either the patients or their families about the health-disease process, nor that there was medical malpractice committed by the physician to be sued. Access to private hospitals is also more common among patients with a higher socioeconomic and educational status, and they have a better understanding of their role as citizens and their rights in society.

In the literature, we found a predominance of neurosurgical malpractice in the spine subspecialty, as in our study. ${ }^{29,36}$ Spine is the largest subspecialty within neurosurgery and made up 58\% of all neurosurgery claims. ${ }^{29}$ Factors increasing the risk of litigation in this subspecialty range from a lack of professionalism to poorly informed consent. ${ }^{37}$ Interestingly, we noted that MTCs in spine procedures were lower than those in the other subspecialties.

Trauma accounts for the second largest malpractice group. ${ }^{36}$ The risk of malpractice lawsuits was consistent in elective, nontrauma, and trauma surgical procedures. ${ }^{29}$ In our study, the brain tumor subspecialty had the most expensive compensation per procedure $(\$ 4050)$. A procedural error in this area was the most common reason for litigation across neurosurgery and the largest median award payouts. ${ }^{38}$

\section{Study Limitations}

In our study, we only considered medical malpractice related to neurosurgery procedures. The reasons for malpractice included failure to diagnose, failure to treat, lack of informed consent, failure to order or refer for diagnostic tests, misinterpretation of test results, unnecessary surgery, and procedural error, which can occur at any moment during patient care and is not necessarily related to the procedure. The limitations of the policies implemented for universalization of the Brazilian health system remain, and the socioeconomic framework in the effects of medical malpractice, mortality, and length of stay should encourage further studies. Nevertheless, JusBrasil is a private platform that compiles lawsuits from all states and higher courts in Brazil and could be subject to errors, such as not reflecting the real number of cases. Moreover, we could not estimate the reason why a plaintiff decided to sue the neurosurgeon, and this decision could be affected by many intangible factors (i.e., patient-physician relationship).

We searched the JusBrasil platform only for the 112 neurosurgery procedures cited in the DATASUS database. Search results are dictated by the search parameters used, and all neurosurgery-related medical malpractice claims might not have been captured by the parameters chosen. Furthermore, the neurosurgical procedure will not necessarily be mentioned in the medical malpractice litigation as described by SUS. Also, JusBrasil does not collect information on claims dropped before formal registration in the legal system or those resolved outside of court.

\section{Conclusions}

The few resources invested in neurosurgical procedures could be directly linked to negative outcomes (i.e., prolonged length of stay and mortality) and higher rates of malpractice lawsuits. Moreover, the social and economic inequalities, the population's awareness of their rights, and the fragility of the doctor-patient relationship could influence a plaintiff's motivation to start a lawsuit and may explain why medical malpractice is still underreported in Brazil.

We encourage new studies correlating the cost-effectiveness of neurosurgical procedures with medical malpractice, mainly in low-income countries, in which there is a lack of financial resources. Furthermore, we recommend better decisions regarding the investments to be made in neurosurgical procedures and more effective actions in reducing medical malpractice.

\section{References}

1. Gomes JCM. Erro médico: reflexões. Rev Bioet. 2009;2(2): 459.

2. Fragata J. Conceito de qualidade em saúde. Risco Clínico: complexidade e performance. 1st ed. Almedina; 2006.

3. Berlin L. Medical errors, malpractice, and defensive medicine: an ill-fated triad. Diagnosis (Berl). 2017;4(3):133-139.

4. Elsamadicy AA, Sergesketter AR, Frakes MD, Lad SP. Review of neurosurgery medical professional liability claims in the United States. Neurosurgery. 2018;83(5):997-1006.

5. Jena AB, Seabury S, Lakdawalla D, Chandra A. Malpractice risk according to physician specialty. $N$ Engl J Med. 2011; 365(7):629-636.

6. McLaughlin N, Garrett MC, Emami L, et al. Integrating risk management data in quality improvement initiatives within an academic neurosurgery department. J Neurosurg. 2016; 124(1):199-206.

7. Maia CS, Freitas DRC, Gallo LG, Araújo WN. Notificações de eventos adversos relacionados com a assistência à saúde que levaram a óbitos no Brasil, 2014-2016. Article in Porguese. Epidemiol Serv Saude. 2018;27(2):e2017320.

8. Couto RC, Pedrosa TMG, Roberto BAD, et al. II anuário da segurança assistencial hospitalar no Brasil. IESS; 2018. Accessed September 9, 2020. https://www.iess.org.br/cms/rep/ Anuario2018.pdf

9. Grimes CE, Henry JA, Maraka J, et al. Cost-effectiveness of surgery in low- and middle-income countries: a systematic review. World J Surg. 2014;38(1):252-263.

10. Murray CJ, Vos T, Lozano R, et al. Disability-adjusted life years (DALYs) for 291 diseases and injuries in 21 regions, 1990-2010: a systematic analysis for the Global Burden of Disease Study 2010. Lancet. 2012;380(9859):2197-2223.

11. Weiss HK, Garcia RM, Omiye JA, et al. A systematic review of neurosurgical care in low-income countries. World Neurosurg X. 2019;5:100068.

12. Silva EN, Silva MT, Pereira MG. Health economic evaluation studies: definition and applicability to health systems and services. Article in Portuguese. Epidemiol Serv Saude. 2016; 25(1):205-207.

13. Ministério da Saúde, Brasil. DATASUS. Accessed September 9, 2020. https://datasus.saude.gov.br

14. Bittencourt SA, Camacho LAB, Leal MDC. Hospital Information Systems and their application in public health. Article in Portuguese. Cad Saude Publica. 2006;22(1):19-30.

15. Instituto Brasileiro de Geografia e Estatística. Divisão Regional Do Brasil. IBGE, Instituto Brasileiro De Geografia e Estatística, 2017. Accessed September 9, 2020. http://www. 
ibge.gov.br/geociencias/organizacao-do-territorio/divisaoregional/15778-divisoes-regionais-do-brasil.html

16. Jurisprudência. Decisões de todos os Tribunais, com busca unificada e gratuita. JusBrasil. Accessed September 9, 2020. http://www.jusbrasil.com.br/jurisprudencia/

17. Bahia L, Scheffer MO. SUS e o setor privado assistencial: interpretações e fatos. Saúde Debate. 2018;42(Spe3):158-171.

18. Dados Gerais. ANS - Agência Nacional De Saúde Suplementar. Accessed September 9, 2020. http://www.ans.gov.br/ perfil-do-setor/dados-gerais

19. Escrivão Junior Á, Rehem R, de Almeida Santos SRR. Desafio da saúde pública e privada do Estado de São Paulo. Revista Debates GVsaúde. 2014(16):7-17.

20. Rimmer A. BMA annual meeting: GMC must recognise that a lack of resources puts doctors at risk of mistakes, says the BMA. BMJ. 2017;357; j3093.

21. Sampaio GB, de Moraes DF, Meguins LC, et al. O custo da neurocirurgia no Sistema Único de Saúde no Hospital de Base de São José do Rio Preto. Arq Bras Neurocir. 2014; 33(3):186-191.

22. Harada MDJCS, Pedreira MDLG, Peterlini MAS, Pereira SR. O Erro Humano e a Segurança do Paciente. Atheneu; 2006.

23. Albuquerque MVD, Viana ALDÁ, de Lima LD, et al. Regional health inequalities: changes observed in Brazil from 2000-2016. Cien Saude Colet. 2017;22(4):1055-1064.

24. Yoon JS, Tang OY, Lawton MT. Volume-cost relationship in neurosurgery: analysis of 12,129,029 admissions from the National Inpatient Sample. World Neurosurg. 2019;129:e791e802.

25. Zygourakis CC, Kahn JG. Cost-effectiveness research in neurosurgery. Neurosurg Clin N Am. 2015;26(2):189-196, viii.

26. Stein SC. Cost-effectiveness research in neurosurgery: we can and we must. Neurosurgery. 2018;83(5):871-878.

27. Awad A, Bader-El-Den M, McNicholas J. Patient length of stay and mortality prediction: a survey. Health Serv Manage Res. 2017;30(2):105-120.

28. Roque KE, Tonini T, Melo ECP. Adverse events in the intensive care unit: impact on mortality and length of stay in a prospective study. Cad Saude Publica. 2016;32(10): e00081815.

29. Thomas R, Gupta R, Griessenauer CJ, et al. Medical malpractice in neurosurgery: a comprehensive analysis. World Neurosurg. 2018;110:e552-e559.

30. Romero ADCB. Professional practice and neurosurgery: what every neurosurgeon should know about malpractice. Arq Bras Neurocir. 2018;37(04):309-316.

31. Bitencourt AGV, Neves NMBC, Neves FBCS, et al. Medical error analysis in ethics investigations: implications on medical education. Article in Portuguese. Rev Bras Educ Med. 2007;31(3):223-228.

32. Minossi JG. Prevention of medico-legal conflicts in medical practice. Article in Portuguese. Rev Col Bras Cir. 2009;36(1): 90-95.
33. Fujita RR, Santos I. A denouncement of medical errors in Goias state. Article in Portuguese. Rev Assoc Méd Bras (1992). 2009;55(3):283-289.

34. Kosoko-Lasaki S, Cook CT, O’Brien RL. Cultural Proficiency in Addressing Health Disparities. Jones \& Bartlett Publishers; 2009.

35. McClellan FM, White AA III, Jimenez RL, Fahmy S. Do poor people sue doctors more frequently? Confronting unconscious bias and the role of cultural competency. Clin Orthop Relat Res. 2012;470(5):1393-1397.

36. Fager CA. Malpractice issues in neurological surgery. Surg Neurol. 2006;65(4):416-421.

37. Agarwal N, Gupta R, Agarwal P, et al. Descriptive analysis of state and federal spine surgery malpractice litigation in the United States. Spine (Phila Pa 1976). 2018;43(14):984-990.

38. Kessler RA, Benzil DL, Loewenstern J, et al. Malpractice litigation in brain tumor surgery: a 31-year analysis of causative factors in the United States from the Westlaw database. World Neurosurg. 2019;122:e1570-e1577.

\section{Disclosures}

The authors report no conflict of interest concerning the materials or methods used in this study or the findings specified in this paper.

\section{Author Contributions}

Conception and design: de Macêdo Filho. Acquisition of data: de Macêdo Filho, Albuquerque. Analysis and interpretation of data: de Macêdo Filho, Albuquerque. Drafting the article: all authors. Critically revising the article: de Macêdo Filho, Aragão, Moura, Albuquerque. Reviewed submitted version of manuscript: de Macêdo Filho, Aragão, Moura, Albuquerque. Approved the final version of the manuscript on behalf of all authors: de Macêdo Filho. Statistical analysis: de Macêdo Filho, Olivier. Administrative/technical/material support: de Macêdo Filho, Albuquerque. Study supervision: de Macêdo Filho, Albuquerque.

\section{Supplemental Information \\ Online-Only Content}

Supplemental material is available online.

Supplemental Table 1. https://thejns.org/doi/suppl/10.3171/ 2020.8.FOCUS20571.

\section{Correspondence}

Leonardo J. M. de Macêdo Filho: Health Science Center, Fortaleza, Ceará, Brazil. leonardomacedofilho@edu.unifor.br. 